\title{
The occurrence and characteristics of endoscopically unexpected malignant degeneration in large rectal adenomas
}

\author{
Maxime E. S. Bronzwaer, MD, ${ }^{1}$ Gijsbert D. Musters, MD, $\mathrm{PhD},{ }^{2}$ Renée M. Barendse, MD, $\mathrm{PhD},{ }^{2}$ \\ Lianne Koens, MD, PhD, ${ }^{3}$ Eelco J. R. de Graaf, MD, PhD, ${ }^{4}$ Pascal G. Doornebosch, MD, PhD, ${ }^{4}$ \\ Matthijs P. Schwartz, MD, PhD, ${ }^{5}$ Esther C. J. Consten, MD, PhD, ${ }^{6}$ Erik J. Schoon, MD, PhD, ${ }^{7}$ \\ Ignace H. J. T. de Hingh, MD, PhD, ${ }^{8}$ Pieter J. Tanis, MD, PhD, ${ }^{2}$ Evelien Dekker, MD, PhD, ${ }^{1}$ \\ Paul Fockens, MD, PhD, ${ }^{1}$ on behalf of the TREND study group
}

Amsterdam, Capelle aan de IJssel, Amersfoort, Eindhoven, the Netherlands

\begin{abstract}
Background and Aims: Large non-pedunculated rectal polyps are most commonly resected by endoscopic mucosal resection (EMR) or transanal endoscopic microsurgery (TEM). Despite pre-procedural diagnostics, unexpected rectal cancer is incidentally encountered within the resected specimen. This study aimed to compare the diagnostic assessment and procedural characteristics of lesions with and without unexpected submucosal invasion.

Methods: A post-hoc analysis of a multicenter randomized trial (TREND study) was performed in which patients with a non-pedunculated rectal polyp of $2: 3 \mathrm{~cm}$ without endoscopic suspicion of invasive growth were randomized between EMR and TEM.

Results: Unexpected rectal cancer was detected in 13\% (27/203) of patients; 15 after EMR and 12 after TEM. Most consisted of low-risk T1 cancers (78\%, n Z 18). There were no differences in the diagnostic assessment between lesions with and without unexpected submucosal invasion. Diagnostic biopsies revealed similar rates of high-grade dysplasia (28\% [7/25] vs 18\% [26/144]). When compared with EMR of adenomas, EMR procedures of unexpected cancers had a lower success rate of submucosal lifting $(60 \%$ vs $93 \%, P<.001)$, were more often assessed as endoscopically incomplete ( $33 \%$ vs $10 \%, P Z$. .01), and were more frequently terminated prematurely $(60 \%$ vs $8 \%, P Z .001)$.

Conclusions: Diagnostic assessment of large non-pedunculated rectal polyps revealed similar characteristics between unexpected cancers and adenomas. Unexpected cancers during EMR were non-lifting in 40\%, endoscopically assessed as incomplete in 33\%, and terminated prematurely in $60 \%$. In treatment-naive patients, these factors should raise suspicion of malignancy and need discussion in a multidisciplinary team meeting for decision on further treatment strategies. (Gastrointest Endosc 2018;87:862-71.)
\end{abstract}

\begin{abstract}
Abbreviations: APC, argon plasma coagulation; APR, abdominoperineal resection; CRC, colorectal cancer; EMR, endoscopic mucosal resection; LAR, low anterior resection; TEM, transanal endoscopic microsurgery.

DISCLOSURE: This research received no specific grant from any funding agency in the public, commercial, or not-for-profit sectors. This is a posthoc analysis of the TREND study, which was sponsored by the Netherlands Organization for Health Research and Development (ZonMw, file number 17092201), which did not have access to outcome data during the trial and did not participate in data analyses or the preparation of the manuscript. Dr Schoon reports personal fees from Boston Scientific, personal fees from Medtronic, personal fees from Olympus, outside the submitted work. Dr Dekker received endoscopic equipment on loan from Fujifilm and Olympus and received research grants from Fujifilm and Olympus, outside the submitted work. Dr Fockens reports personal fees from Covidien, personal fees from Fujifilm, personal fees from Olympus, outside the submitted work.
\end{abstract}

Copyright a 2018 by the American Society for Gastrointestinal Endoscopy
$0016-5107 / \$ 36.00$

https://doi.org/10.1016/j.gie.2017.09.046

Received June 30, 2017. Accepted September 24, 2017.

Current affiliations: Department of Gastroenterology and Hepatology (1), Department of Surgery (2), Department of Pathology (3), Academic Medical Center, University of Amsterdam, Amsterdam; Department of Surgery, IJsselland Hospital, Capelle aan de Ijssel (4); Department of Gastroenterology and Hepatology (5), Department of Surgery (6), Meander Medical Center, Amersfoort; Department of Gastroenterology and Hepatology (7), Department of Surgery (8), Catharina Hospital, Eindhoven, the Netherlands.

Reprint requests: Prof. dr. P. Fockens, Department of Gastroenterology and Hepatology, Academic Medical Centre, University of Amsterdam, Room C2-330, 1105 AZ Amsterdam, the Netherlands.

If you would like to chat with an author of this article, you may contact Dr Fockens at p.fockens@amc.nl. 


\section{INTRODUCTION}

Colorectal cancer (CRC) is one of the most prevalent causes of cancer-related deaths in the western world. ${ }^{1}$ Early endoscopic detection and removal of colorectal adenomas, a precursor lesion of CRC, is known to reduce $\mathrm{CRC}$ incidence and mortality. ${ }^{2,3}$ In the western world, large $(\mathrm{B} \mathrm{cm})$ non-pedunculated colorectal polyps are most commonly resected by piecemeal endoscopic mucosal resection (EMR). This technique is safe and effective. ${ }^{4,5}$ However, it is associated with significant local recurrence rates requiring surveillance colonoscopies and additional endoscopic treatment attempts. ${ }^{6}$ When large non-pedunculated polyps are located in the rectum, transanal endoscopic microsurgery (TEM) can also be performed. ${ }^{7}$ TEM enables en bloc polyp resection by either full-thickness or submucosal rectal wall excision. ${ }^{8}$

Large non-pedunculated colorectal polyps may demonstrate endoscopic risk factors of submucosal invasion, such as a depressed morphology (Paris classification type 0-IIc), mucosal friability, Kudo pit pattern type V, NICE classification type 3, non-granularity or the presence of nodules larger than $10 \mathrm{~mm}$ occurring in laterally spreading lesions, and the non-lifting sign present in treatment-naive lesions. ${ }^{4,5,9}$ Despite endoscopic investigation of the known endoscopic risk factors, unexpected cancers are diagnosed incidentally after local endoscopic resection of large nonpedunculated rectal polyps. ${ }^{9-12}$ Little is known about the endoscopic characteristics of these unexpected cancers diagnosed in large rectal adenomas that appear benign during colonoscopy. Therefore, the aim of this study was to compare the diagnostic assessment of unexpected rectal cancers and histologically proven rectal adenomas based on a post-hoc analysis of a multicenter randomized trial. ${ }^{13}$ Furthermore, procedural characteristics of piecemeal EMR and transmural TEM were compared between lesions with and without unexpected submucosal invasive disease.

\section{METHODS}

\section{Patients}

Patients included in this post-hoc analysis were selected from a randomized trial (TREND study) comparing recurrence rates of large rectal adenomas within 24 months after either piecemeal EMR or transmural TEM. ${ }^{13,14}$ Patient recruitment took place between 2009 and 2013 in 17 Dutch hospitals, of which 4 were academic centers, and 1 Belgian academic center. The study protocol was approved by the Institutional Review Board of each participating center and written informed consent was obtained from all patients.

Patients were eligible when diagnosed with a large $2: 3$ $\mathrm{cm})$ non-pedunculated rectal adenoma without endoscopic characteristics of submucosal invasion, and if at least $50 \%$ of the adenoma was situated within $15 \mathrm{~cm}$ from the dentate line. Endoscopists were requested to use the Paris classification to describe lesion morphology and the Kudo pit pattern to classify the mucosal pattern. The Kudo pit pattern was evaluated with white-light endoscopy and virtual chromoendoscopy, such as narrow-band imaging (NBI), flexible spectral imaging color enhancement (FICE), or I-scan. Virtual chromoendoscopy was only used at the discretion of the endoscopist and was dependent on the availability of virtual chromoendoscopy equipment in the endoscopy centers. ${ }^{15,16}$ Exclusion criteria were endoscopic features of malignant progression defined as a Kudo pit pattern $\mathrm{V}$, clear excavation or depression of the lesion, and, if conducted, histology showing submucosal invasion. A pre-procedural rectal EUS was allowed but not a prerequisite for inclusion in the study. EUS was advised when submucosal invasion could not be completely excluded endoscopically. If EUS showed suspicion of invasive growth, the gastroenterologist or gastrointestinal surgeon in the participating hospital made decisions of patient inclusion based on the endoscopic findings. Suspicion of invasive growth by EUS was not an absolute exclusion criterion for inclusion in the TREND study, because EUS is known to be associated with significant interobserver variability for assessing submucosal invasion and limited diagnostic accuracy in daily clinical practice. ${ }^{14,17}$

Once histopathologic evaluation of the resection specimen revealed malignant degeneration despite adherence to the inclusion criteria, the patient was included in this post-hoc analysis. Patients underwent additional surgical treatment or surveillance according to the national rectal cancer guidelines. ${ }^{18}$ All patients were discussed during multidisciplinary team meetings in the participating centres where the final treatment was agreed upon. Surveillance involved chest radiographs, ultrasonography or $\mathrm{CT}$ of the abdomen and pelvis and/or magnetic resonance imaging (MRI) or CT of the pelvis.

\section{Intervention strategies}

Piecemeal EMR was performed as described by Karita et $\mathrm{al}^{19}$ and Hurlstone et ${ }^{2} .^{20}$ Argon plasma coagulation (APC) was used to treat potential remnants within the resection plane and was appointed to be used prophylactically on the edges of the mucosal defect according to the study protocol. Procedures were performed by experienced endoscopists, and an expert panel evaluated a video-recorded procedure by each participating endoscopist before inclusion of patients. TEM was performed as described by Buess et $\mathrm{al}^{7}$ and was performed by experienced surgeons following a formal training program for TEM. Both intervention strategies are described in more detail elsewhere. ${ }^{13,14}$

\section{Histopathologic evaluation}

After EMR, all the resected pieces were collected for histopathologic evaluation and were directly immersed in formalin. Resection specimens after TEM were stretched and pinned on cork or paraffin before immersion in 
formalin. ${ }^{14}$ If malignant progression was present, additional characteristics, including tumor size, differentiation grade, infiltration depth according to the TNM staging system and Sm stage in case of a T1 cancer, venous invasion, lymphatic invasion, and resection margins, were evaluated. ${ }^{21}$ These additional characteristics of the surgical resection specimen were also recorded when completion surgery was performed. When rectal cancer was diagnosed, the histopathology slides of the EMR or TEM specimen as well as the specimen from the completion surgical procedure were reviewed centrally by a dedicated gastrointestinal pathologist (L.K.). The reported histopathologic characteristics were based on the surgical resection specimen when additional surgical resection was performed. If not, the characteristics of the EMR or TEM specimen were described.

\section{Outcome parameters}

The diagnostic work-up of unexpected rectal cancers and histopathologically proven rectal adenomas was compared based on diameter, Paris classification, Kudo pit pattern, biopsy results ifdiagnostic biopsies were taken, and for those who underwent EUS, suspicion of invasive growth and clinical lymph node status. EMR procedures of unexpected cancers and adenomas were evaluated regarding the percentage of successful lifting, endoscopic judgement of completeness, and early termination of the procedure. TEM procedures were evaluated regarding en bloc as well as full-thickness resection rates. The additional surveillance strategy or surgical treatment of the unexpected rectal cancers and the occurrence of local recurrences and distant metastasis were evaluated. Data concerning the long-term follow-up data, such as the occurrence of local recurrences and distant metastasis, were collected retrospectively.

\section{Statistical analysis and ethical considerations}

The descriptive data are reported as medians with interquartile range (IQR) or meanststandard deviation according to the distribution of the data. Categorical data were analyzed with the Chi-square test or the Fisher exact test, where appropriate. Numerical data were analyzed using the Student t test or Mann-Whitney U test according to the distribution. A $P$ value $<.05$ was considered statistically significant. Bonferroni correction was used when multiple comparisons were performed in order to decrease the chance of incorrect rejection of the null hypothesis due to multiplicity. Statistical analysis was performed using SPSS 24 (SPSS, Chicago, Ill).

\section{RESULTS}

\section{Patients}

A total of 203 patients were included in the analysis of the TREND study. ${ }^{13}$ Of these patients, 27 (13\%) were diagnosed with an unexpected rectal cancer; 15 were treated initially with EMR and 12 with TEM. There were no differences in the baseline patient characteristics between the unexpected rectal cancers and the histologically proven rectal adenomas included in the TREND study (Table 1). Rectal blood loss was reported more frequently by patients with cancer than those with a benign lesion ( $82 \%$ vs $52 \%, P Z$.004). Unexpected rectal cancers were equally distributed among participating centers (data not shown).

\section{Lesion characteristics}

The mean size of the unexpected rectal cancers was $47.0 \pm 11.8 \mathrm{~mm}$ as shown in Table 2 . Most (75\%, n Z 21) had a sessile (Is) morphology, and a Kudo pit pattern III-L or IV was seen in $15 \%$ or $30 \%$. The Paris classification and Kudo pit patterns were not described in $15 \%$ and $56 \%$ of the patients, respectively. Figures 1 and 2 show the endoscopic images of one case of an unexpected cancer and one case found not to have malignant degeneration after resection.

Fourteen of the $27(52 \%)$ patients with unexpected rectal cancer underwent EUS before treatment, which showed benign features of a T0 lesion in 9 patients (64\%). In the 5 remaining cases, the ultrasonographer did not draw a definitive conclusion on the invasion depth. These patients were not excluded from the study because suspicion of invasive growth on EUS was not an absolute exclusion criterion. Eligibility for the TREND study was determined on the discretion of the gastroenterologist or gastrointestinal surgeon. In these patients, endoscopic findings were leading. In 25 (93\%) patients, diagnostic biopsy specimens were taken before the resection, showing low-grade dysplasia in 18 patients $(72 \%)$ and high-grade dysplasia in 7 patients $(28 \%)$. The results of diagnostic assessment of the unexpected rectal cancers were not significantly different from the histologically proven adenomas.

\section{Procedural characteristics}

For piecemeal EMR, the success rate of submucosal lifting was significantly lower in the unexpected cancers compared with the benign adenomas $(60 \%$ vs $93 \%, P<$ .001 ; further details in Table 3). Endoscopic resections, including per protocol APC treatment of the edges of the mucosal defect and potential remnants within the resection defect, were significantly more often judged as macroscopically incomplete in malignant lesions than in benign adenomas $(60 \%$ vs $85 \%, P Z$.01). Early termination of the procedure occurred more often during treatment of unexpected malignant lesions $160 \%$ vs $8 \%, P$ Z .001). No significant differences were found in other procedural characteristics, including the procedural or post-procedural adverse event rates. 
TABLE 1. Demographics of the patients with an unexpected rectal cancer compared with those with histologically proven benign adenomas

\begin{tabular}{|c|c|c|c|}
\hline \multirow[b]{3}{*}{ Gender, n (\%) } & \multicolumn{3}{|c|}{ Total study cohort (n [203) } \\
\hline & $\begin{array}{l}\text { Rectal } \\
\text { cancers } \\
\text { (n \27) }\end{array}$ & $\begin{array}{l}\text { Benign } \\
\text { adenomas } \\
\text { (n โ176) }\end{array}$ & $P$ value \\
\hline & & & .57 \\
\hline Male & $16(59)$ & $94(53)$ & \\
\hline Female & $11(41)$ & $82(47)$ & \\
\hline Age (years), mean \pm SD & $67.4 \pm 8.6$ & $66.8 \pm 10.5$ & .78 \\
\hline $\begin{array}{l}\text { American Society of } \\
\text { Anesthesiologists (ASA) } \\
\text { classification, } n(\%)\end{array}$ & & & .20 \\
\hline I: Healthy & $11(41)$ & $89(51)$ & \\
\hline $\begin{array}{l}\text { II: Mild systemic } \\
\text { disease }\end{array}$ & $16(59)$ & $77(44)$ & \\
\hline $\begin{array}{l}\text { III: Severe systemic } \\
\text { disease }\end{array}$ & - & $10(5.0)$ & \\
\hline $\begin{array}{l}\text { Body mass index, } \\
\mathrm{kg} / \mathrm{m} 2 \pm \mathrm{SD}\end{array}$ & $26.2 \pm 4.2$ & $25.8 \pm 3.7$ & .57 \\
\hline Anticoagulant use, $n(\%)$ & $9(33)$ & $41(23)$ & .26 \\
\hline Antiplatelet agents & $1(4)$ & $22(13)$ & .32 \\
\hline Vitamin $\mathrm{K}$ antagonists & $8(30)$ & $24(14)$ & $.05^{*}$ \\
\hline Symptoms, n (\%) & $27(100)$ & $160(91)$ & .10 \\
\hline Rectal blood loss & $22(82)$ & $92(52)$ & .004 \\
\hline Fecal incontinence & - & $9(5)$ & .23 \\
\hline Changed bowel habits & $22(82)$ & $111(63)$ & .06 \\
\hline Fecal urgency & $11(41)$ & $60(34)$ & .50 \\
\hline Prolapse & $1(6)$ & $21(16)$ & .28 \\
\hline Hospital type, n (\%) & & & .36 \\
\hline Academic & 5 (19) & $47(27)$ & \\
\hline Regional & $22(82)$ & $129(73)$ & \\
\hline
\end{tabular}

$S D$, Standard deviation.

*Remained not significant after Bonferroni correction.

\section{Histopathologic evaluation of unexpected cancers}

The majority of the unexpected cancers consisted of $\mathrm{T} 1$ cancers (n Z 22, 82\%); 3 T2 (11\%) and 2 T3 cancers $(7 \%)$ were identified. Eighteen cancers $(78 \%)$ were well to moderately differentiated and had no lymphatic or venous invasion. None of the lymph nodes retrieved after radical completion surgery were positive for metastasis (Table 4).

\section{Additional surgical treatment of unexpected cancers}

After diagnosis of rectal cancer, 12 of $15(80 \%)$ patients who were primarily treated with EMR and 5 of $12(42 \%)$ patients with initial TEM underwent completion surgery (odds ratio, 5.6; 95\% confidence interval, 1.02-30.90; P Z .04). After EMR, 6 patients underwent TEM, 2 underwent abdomino-perineal resection (APR), and 4 low anterior
TABLE 2. Results of diagnostic assessment of the unexpected rectal cancers compared with the histologically proven benign adenomas

\begin{tabular}{|c|c|c|c|}
\hline \multirow[b]{3}{*}{ Diameter $(\mathrm{mm})$, mean $\pm \mathrm{SD}$} & \multicolumn{3}{|c|}{ Total study cohort (n [203) } \\
\hline & $\begin{array}{l}\text { Rectal } \\
\text { cancers } \\
\text { (n โ27) }\end{array}$ & $\begin{array}{l}\text { Benign } \\
\text { adenomas } \\
\text { (n โ176) }\end{array}$ & value \\
\hline & $47.0 \pm 11.8$ & $46.5 \pm 16.0$ & .88 \\
\hline $\begin{array}{l}\text { Distance from anal } \\
\text { verge }(\mathrm{cm}) \text {, mean } \pm \text { SD }\end{array}$ & $6.2 \pm 3.6$ & $5.2 \pm 4.1$ & .21 \\
\hline Paris classification, n (\%) & & & .33 \\
\hline Ip & - & $1(1)$ & \\
\hline Is & $20(74)$ & $93(53)$ & \\
\hline Ila & $3(11)$ & $39(22)$ & \\
\hline Unknown & $4(15)$ & $43(24)$ & \\
\hline Kudo classification, n (\%) & & & .52 \\
\hline III-S & - & $5(3)$ & \\
\hline III-L & $4(15)$ & $43(24)$ & \\
\hline IV & $8(30)$ & $48(27)$ & \\
\hline Unknown & $15(56)$ & $80(46)$ & \\
\hline EUS, n (\%) & & & .09 \\
\hline Yes & $14(52)$ & $54(31)$ & \\
\hline No & $13(48)$ & $120(68)$ & \\
\hline Missing & - & $2(1)$ & \\
\hline EUS stage, $\mathrm{n}(\%)$ & & & .14 \\
\hline T0 & $9(64)$ & $38(70)$ & \\
\hline T1-T3 & $4(29)$ & $16(30)$ & \\
\hline Missing & $1(7)$ & - & \\
\hline EUS Iymph nodes, n (\%) & & & .10 \\
\hline No & $11(79)$ & $51(94)$ & \\
\hline Missing & $3(21)$ & $3(6)$ & \\
\hline $\begin{array}{l}\text { Pre-procedure } \\
\text { biopsies, } n(\%)\end{array}$ & & & .16 \\
\hline No & $2(7)$ & $32(18)$ & \\
\hline Yes & $25(93)$ & $144(82)$ & \\
\hline Adenoma subtype, n (\%) & & & .19 \\
\hline Tubular & $1(4)$ & $17(12)$ & \\
\hline Tubulovillous & $12(48)$ & $82(57)$ & \\
\hline Villous & $12(48)$ & $41(29)$ & \\
\hline Missing & - & $4(3)$ & \\
\hline Grade of dysplasia, $n$ (\%) & & & .38 \\
\hline Low-grade dysplasia & $18(72)$ & $114(79)$ & \\
\hline High-grade dysplasia & $7(28)$ & $26(18)$ & \\
\hline Missing & - & $4(3)$ & \\
\hline
\end{tabular}

SD, Standard deviation.

resection (LAR). After TEM, 1 patient underwent LAR and the remaining 4 patients APR. All additional surgery was performed within 6 months (median, 2 months; IQR, 1.04.75 months) after the diagnosis of unexpected rectal cancer. The type of surgery and surgery-related adverse events 

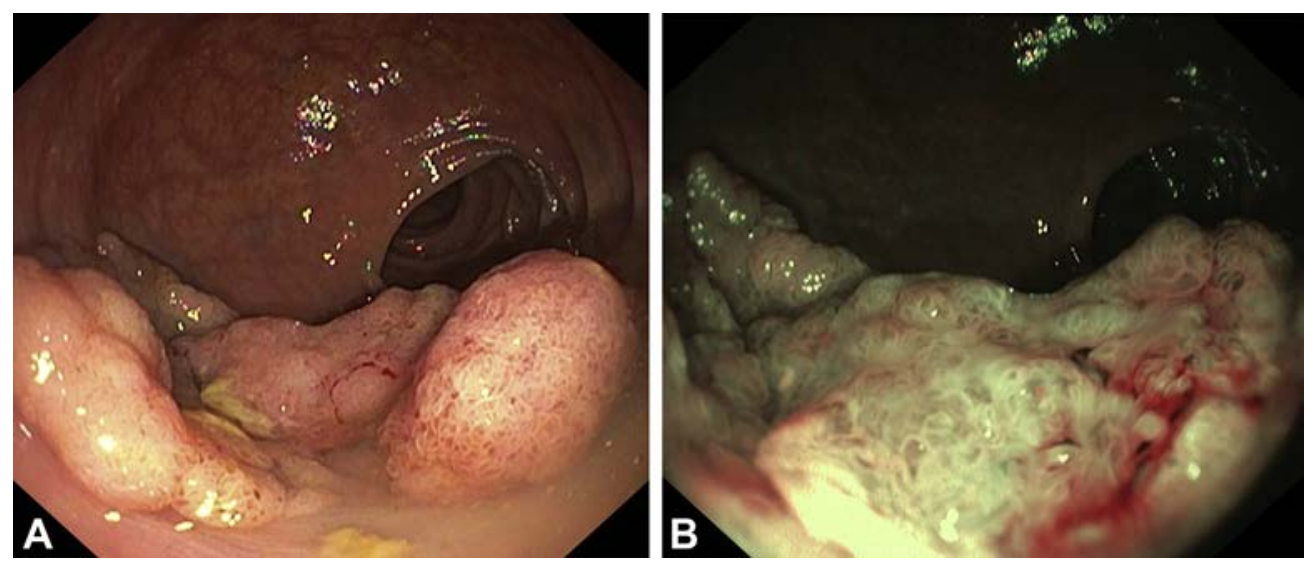

Figure 1. Endoscopic pictures of a case of an unexpected rectal cancer included in the post-hoc analysis of the TREND study. A, White-light endoscopy image of an unexpected rectal cancer; B, virtual chromoendoscopy image of an unexpected rectal cancer.
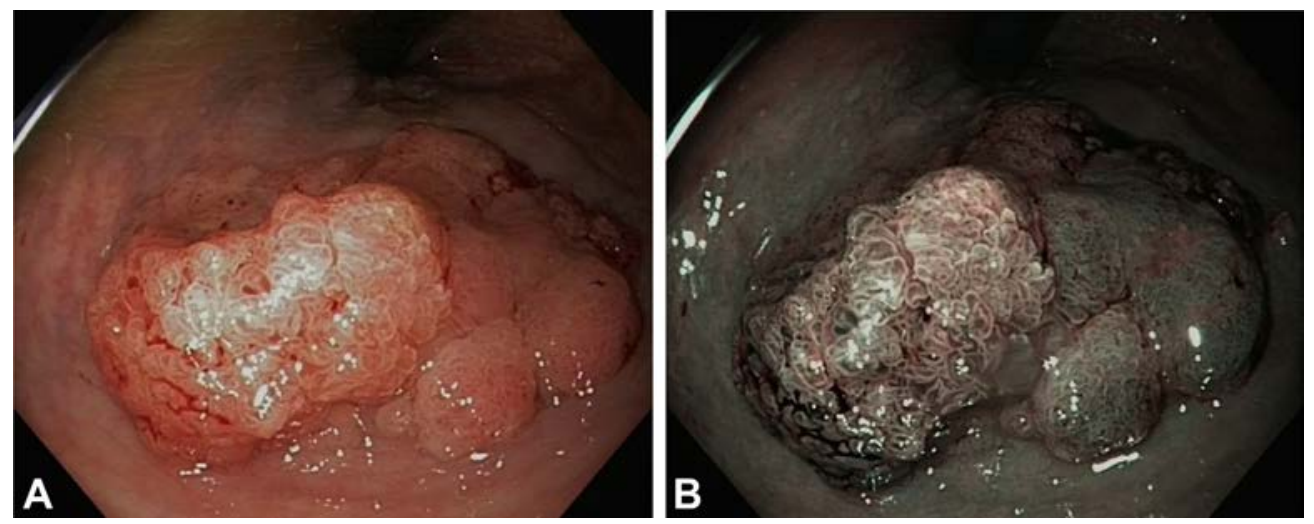

Figure 2. Endoscopic images of a case of a benign adenoma without malignant degeneration included in the TREND study. A, White-light endoscopy image of a rectal tublovillous adenoma with low-grade dysplasia; B, virtual chromoendoscopy image of a rectal tublovillous adenoma with low-grade dysplasia.

were not significantly different after EMR or TEM (Table 5). Supplementary Table 1 (available at www.giejournal.org) shows that no cancers were downgraded, but the tumor stage of 3 cancers primarily treated with EMR was upgraded after completion surgery. In contrast, no cancers were upgraded or downgraded after completion surgery following TEM. In a total of 9 patients ( 4 after initial TEM and 5 after initial EMR), no residual cancer was detected in the completion resection specimen.

\section{Follow-up/survival data}

After a mean follow-up of $4.4 \boxplus .2$ years, overall survival was $100 \%$. One locally recurrent rectal cancer (4\%) was detected after 22 months during a planned surveillance colonoscopy. This recurrence occurred after TEM of a well-differentiated T1Sm1 cancer without lymphatic or venous invasion and with complete margins. The recurrence turned out to be a well-differentiated T3N1M0 rectal cancer, which was additionally treated by LAR after neoadjuvant chemoradiotherapy.

Distant metastases were found in 3 patients $(11 \%)$, all of whom underwent surveillance after TEM of moderate to well-differentiated T1Sm3 rectal cancers without lymphatic or venous invasion and with complete margins after 34,63 , and 72 months, respectively. One of those patients underwent completion TEM because of the inability to assess the resection margins after EMR. Metastases consisted of pulmonary metastases in 2 patients and a solitary liver metastasis in 1 . One patient with pulmonary metastases underwent palliative treatment; the other received intentionally curative radiotherapy. The patient with liver metastasis was treated surgically.

\section{DISCUSSION}

Despite pre-procedural diagnostics, unexpected rectal cancers were encountered in $13 \%$ of large nonpedunculated rectal polyps that appeared benign. This seems comparable with reported incidences of malignant degeneration in these lesions $(6.9 \%-14 \%) .^{9-12}$ This posthoc analysis did not reveal any significant differences in diagnostic findings between the unexpected cancers and the histologically proven adenomas. Unexpected cancers 


\begin{tabular}{|c|c|c|c|c|}
\hline \multirow[b]{3}{*}{ Endoscopic radical resection overall, $n$ (\%) (EMR procedures only) } & \multicolumn{4}{|c|}{ Total study cohort (n [203) } \\
\hline & $\begin{array}{l}\text { Malignant } \\
\text { lesions } \\
\text { (n [27) }\end{array}$ & $\begin{array}{l}\text { Benign } \\
\text { adenomas } \\
\text { (n [ 176) }\end{array}$ & $P$ value & $\begin{array}{c}\text { Odds ratio } \\
\text { (95\% confidence } \\
\text { interval) }\end{array}$ \\
\hline & & & .01 & $0.22(0.06-0.80)$ \\
\hline Missing & $1(7)$ & $4(5)$ & & \\
\hline Early termination of the procedure, $n$ (\%) (EMR procedures only) & & & .001 & $0.13(0.04-0.48)$ \\
\hline No & $6(40)$ & $80(98)$ & & \\
\hline Yes & $9(60)$ & $7(8)$ & & \\
\hline Missing & - & $1(1)$ & & \\
\hline Procedural time (minutes), median (IQR) & $67(42-87)$ & $60(40-86)$ & .95 & \\
\hline Admission duration (days), median (IQR) & $1.0(0-1)$ & $1.0(0-2)$ & .37 & \\
\hline Full-thickness resection, $n$ (\%) (TEM procedures only) & & & .45 & \\
\hline No & 1 (8) & $14(16)$ & & \\
\hline Yes & $11(92)$ & $76(84)$ & & \\
\hline En bloc resection, $n$ (\%) (TEM procedures only) & & & .21 & \\
\hline No & - & $10(11)$ & & \\
\hline Yes & $12(100)$ & $80(89)$ & & \\
\hline Post-procedural adverse events per patient, $\mathrm{n}$ (\%) & $4(15)$ & $39(22)$ & .38 & \\
\hline Clavien-Dindo, n (\%) & & & .35 & \\
\hline 1 & - & $11(22)$ & & \\
\hline II & $3(50)$ & $9(18)$ & & \\
\hline IIla & $2(33)$ & $21(42)$ & & \\
\hline IIIb & - & $5(10)$ & & \\
\hline IV & $1(17)$ & $3(6)$ & & \\
\hline V & - & $1(2)$ & & \\
\hline
\end{tabular}

IQR, Interquartile range; TEM, transanal endoscopic microsurgery.

during EMR were non-lifting in 40\%, endoscopically assessed as incomplete in $33 \%$, and procedures were terminated prematurely in 60\%; all these proportions were significantly higher compared with EMR of ultimately proven adenomas. Most of the unexpected cancers were low-risk T1, and none were found to belymph node positive in case of radical completion surgery, resulting in excellent long-term oncologic outcomes.

There are several techniques to increase the overall diagnostic accuracy of submucosally invasive disease, but further improvement is required. Advanced imaging techniques such as virtual chromoendoscopy and magnifying endoscopy have been acknowledged to improve the identification of morphological features suggestive of submucosal invasion, such as irregular or absent surface vascular patterns (Kudo V pit pattern or NICE classification type 3). ${ }^{5,22-24}$ Both classification systems are associated with a learning curve and interobserver variability. Several training modules are described to improve optical diagnosis with advanced imaging techniques, ${ }^{5,22}$ but none 
TABLE 4. Staging of the unexpected rectal cancers*

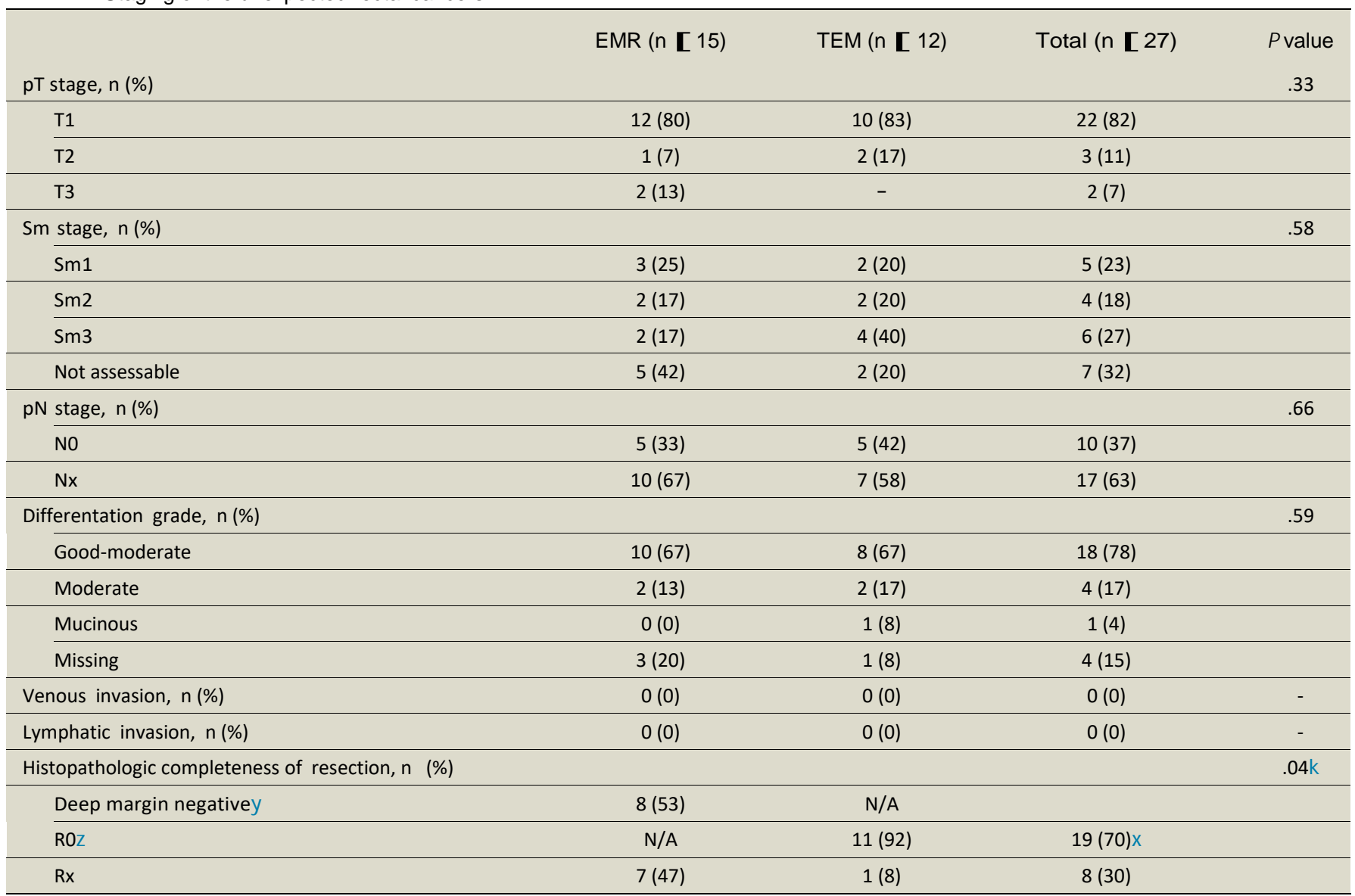

TEM, Transanal endoscopic microsurgery; N/A, not available.

*Previously published data. ${ }^{13}$ If patients underwent completion surgery, the resection specimen was used for tumor staging. If no completion surgery was performed, the tumor stage based on the EMR or TEM specimen was used.

YEMR procedures only.

ZTEM: RO when the basal and lateral margins were free of malignancy.

XThe total histopathologic completeness resections are the deep margin negative EMR procedures and RO TEM procedures taken together.

kRemained not significant after Bonferroni correction.

focus primarily on endoscopic recognition of submucosal invasion in large non-pedunculated colorectal lesions. In addition, all published data are derived from expert endoscopy centers. ${ }^{5,22,24,25}$ Therefore, the applicability of these classification systems for the identification of suggestive features of submucosal invasion remains unknown in daily practice.

To determine the presence of an invasive component in large non-pedunculated rectal lesions, random diagnostic mucosal biopsies can be included in the diagnostic workup. As both benign and malignant parts are usually present in these unexpected cancers, biopsies are associated with an inherent sampling error. ${ }^{26}$ This implies a chance of underdiagnosis and therefore random diagnostic biopsies should not be used for a reliable diagnosis and determination of additional treatment strategies unless targeted biopsies are taken from highly suspicious areas in order to prove malignancy. ${ }^{5}$ Accordingly, in our series, biopsy samples were taken from almost all lesions, and the distribution of low-grade and high-grade dysplasia did not differ between the unexpected cancers and proven benign adenomas.

Also, EUS can be used as a diagnostic modality for clinical staging of rectal lesions. A $97.3 \%$ sensitivity and $96.3 \%$ specificity for large benign rectal adenomas was found in EUS expert centers. ${ }^{27}$ Within these expert centers, EUS is the most accurate imaging modality to discriminate between $\mathrm{T} 1$ and $\mathrm{T} 2$ rectal cancer. However, it is associated with a low accuracy in discriminating $\mathrm{T} 1$ substages, such as $\mathrm{sm} 1, \mathrm{sm} 2$, and sm3. The quality of EUS is highly dependent upon the experience of the diagnosing physician, which is underlined by a clearly lower accuracy of EUS in daily clinical practice. ${ }^{17}$

In addition to the pre-procedural endoscopic risk features of colorectal lesions, the procedural non-lifting sign is also associated with an increased risk of submucosal invasion, as confirmed in the present study. ${ }^{28}$ However, nonlifting can also be caused by fibrosis, which may be the result of previous treatment attempts, taking diagnostic 


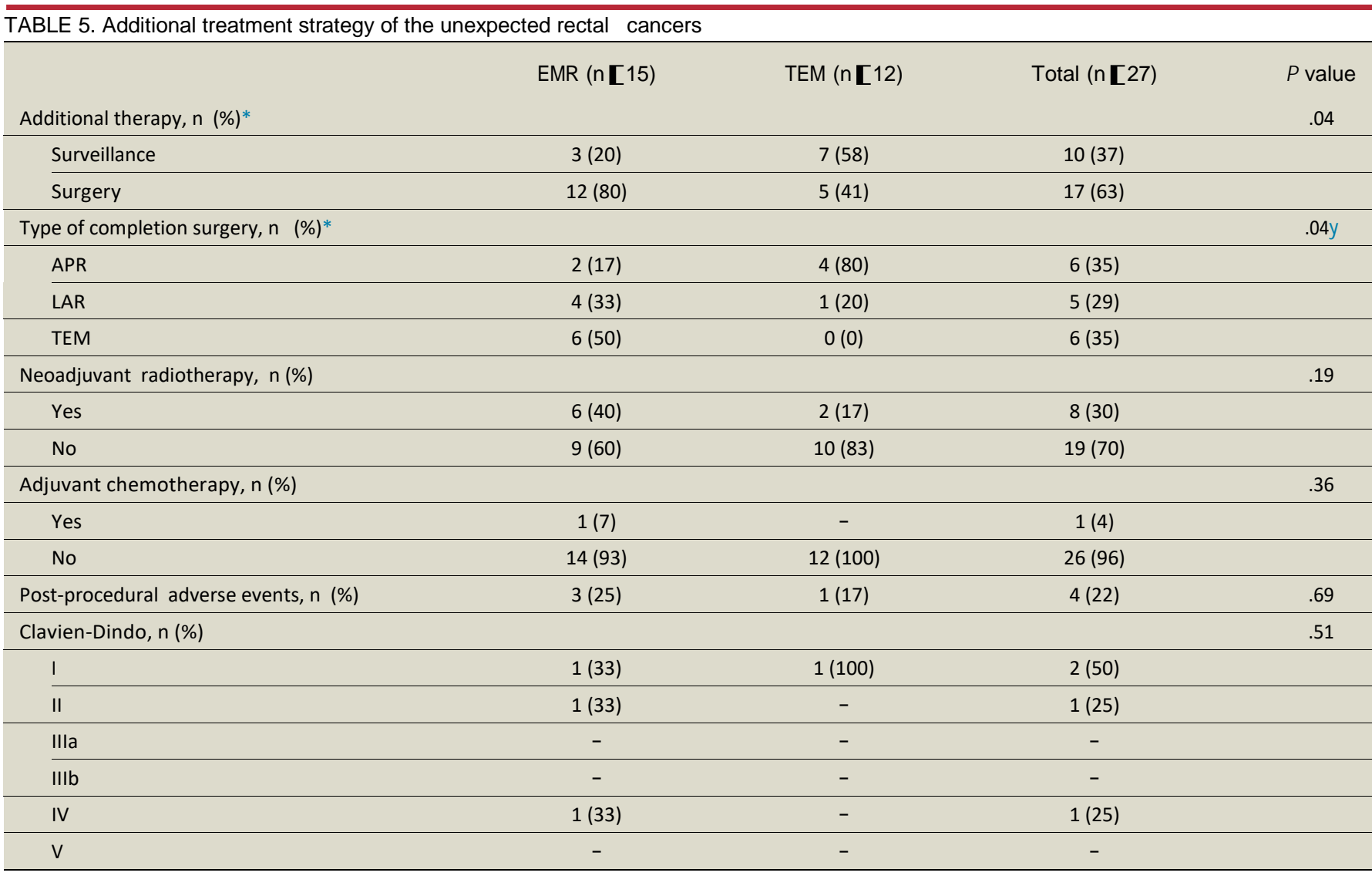

$A P R$, Abdominoperineal resection; LAR, low anterior resection; TEM, transanal endoscopic microsurgery.

*Previously published data. ${ }^{13}$

yRemained not significant after Bonferroni correction.

biopsy specimens, or as a reaction to submucosal injection. ${ }^{5,9,29}$ When non-lifting occurs in flat or sessile treatment-naive lesions during EMR, a suspicion of malignancy should rise and abandoning the procedure should be considered.

This post-hoc analysis showed that the need for completion surgery was significantly higher afterEMR, but the proportion of radical total mesorectal excision (TME) was comparable between EMR and TEM. ${ }^{13}$ In contrast to TEM, after piecemeal EMR, endoscopists and pathologists are unable to assess invasion depth and resection margins, which commonly necessitates additional surgery, even in the absence of other risk factors. ${ }^{18}$ Therefore, in patients with endoscopic suspicion of submucosal invasion, a piecemeal resection should be avoided. ${ }^{4,5}$ Patients with a low-risk T1 cancer (well to moderately differentiated, no lymphatic or venous invasion, and clear resection margins) initially treated with piecemeal EMR can thereafter be treated with full-thickness TEM. After this local resection without additional radical completion surgery or chemoradiotherapy, these patients have acceptable oncologic outcomes with local recurrence rates of less than $5 \%$ and a limited risk of lymph node metastasis. ${ }^{30,31}$

It is generally advised that high-risk T1 cancers (poorly differentiated, lymphatic or venous invasion) and higher
T stages should be treated with radical completion surgery. This is because of higher local recurrence rates (up to 25\%) and a more than $10 \%$ risk of lymph node metastasis. ${ }^{10,30,31}$ This strategy is also endorsed by Dutch and European guidelines. ${ }^{18,32}$ Good oncologic outcomes are achieved after this completion surgical resection with a 5-year diseasefree survival rate of approximately 95\%, local recurrence rates of about $5 \%$, and distant recurrence rates of less than $10 \% .{ }^{33-38}$ Comparable and adequate oncologic outcomes are found in the present study with a lymph node metastasis rate of $4 \%$, a subsequent local rectal cancer recurrence rate of $4 \%$, and distance metastases rate of $11 \%$. However, because of the limited follow-up period and the small number of patients in this analysis, caution is required when interpreting these results.

Our study has certain limitations. First, advanced imaging techniques were only used at the discretion of the endoscopist and the availability and experience of these techniques in the endoscopy centers, reflecting daily practice during the study period (2009-2013). Therefore, the Kudo pit pattern was described in only half of the patients, which could have been one of the causes of misclassification of the unexpected rectal cancers. Second, the histopathologic handling of the EMR and TEM specimens is inherently different. A pinned down TEM specimen allows 
more precise determination for the presence of invasive cancer as well as the resection margins, whereas incomplete margins and invasive cancer could be missed on the multiple EMR specimens, which were just immersed in formalin. In addition, due to the fragmentation of the EMR specimen, it is difficult to reliably assess tumor invasion depth, which was also shown in our study as the tumor stage of 3 unexpected cancers primarily treated with EMR were upgraded in tumor stage after completion surgery. In contrast, no cancers were upgraded or downgraded after completion surgery following TEM. Caution is required when interpreting these results because only a limited number of patients underwent completion surgery after EMR and TEM. Another limitation of the study is the retrospective collection of long-term follow-up data, such as the occurrence of local recurrences and distant metastasis. Lastly, the absolute number of patients that appeared to have an unexpected cancer is relatively small.

To the best of our knowledge, this is the first study describing the occurrence as well as the proceduralcharacteristics of unexpected rectal cancers after endoscopic and ultrasonographic preoperative lesion assessment in daily practice. In conclusion, there were no differences in preprocedural diagnostics that could already have indicated the presence of invasive growth. During EMR, non-lifting, endoscopically assessed irradical resection, or early termination were associated with unexpected cancers. This should raise suspicion of malignancy in treatment-naïve patients, whereafter the patient should be discussed in a multidisciplinary team meeting in which additional tailored en bloc full-thickness resection with TEM or completion surgery should be considered.

\section{ACKNOWLEDGMENTS}

The TREND study group consists of the following: Willem A. Bemelman (Department of Surgery, Academic Medical Center, University of Amsterdam, Amsterdam, the Netherlands); Bart Bijnen (Department of Surgery, Medical Center Alkmaar, Alkmaar, the Netherlands); Raf Bisschops (Department of Gastroenterology, University Hospital Leuven, Leuven, Belgium); Frank J.C. van den Broek(Department of Surgery, Maxima Medisch Centrum, Velthoven, the Netherlands); Paul Davids (Department of Surgery, Diakonessenhuis, Utrecht, the Netherlands); Annekatrien Depla (Department of Gastroenterology, Slotervaart Hospital, Amsterdam, the Netherlands); Hendrik van Dullemen (Department of Gastroenterology, University Medical Center Groningen, Groningen, the Netherlands); James C. Hardwick (Department of Gastroenterology, Leiden University Medical Center, Leiden, the Netherlands); Chrisiaan Hoff (Department of Surgery, Medical Center Leeuwarden, Leeuwarden, the Netherlands); Martin Houben(Department of Gastroenter- ology, Haga Teaching Hospital, the Hague, the Netherlands); Jeroen M. Jansen (Department of Gastroenterology, Onze Lieve Vrouwe Gasthuis, Amsterdam, the Netherlands); Michael F. Gerhards (Department of Surgery, Onze Lieve Vrouwe Gasthuis, Amsterdam, the Netherlands); Klaas van der Linde (Department of Gastroenterology, Medical Center Leeuwarden, Leeuwarden, the Netherlands); A.W. Marc van Milligen de Wit (Department of Gastroenterology, Amphia Hospital, Breda, the Netherlands); Rosalie Mallant (Department of Gastroenterology, Flevo Hospital, Almere, the Netherlands); George P. van der Schelling (Department of Surgery, Amphia Hospital, Breda, the Netherlands); Robin Timmer (Department of Gastroenterology, St. Antonius Hospital, Nieuwegein, the Netherlands); Ben Witteman (Department of Gastroenterology, Gelderse Vallei Hospital, Ede, the Netherlands); Bas L.A.M. Weusten (Department of Gastroenterology, St. Antonius Hospital, Nieuwegein, the Netherlands); Albert Wolthuis (Department of Surgery, University Hospital Leuven, Leuven, Belgium).

\section{REFERENCES}

1. Torre LA, Bray F, Siegel RL, etal. Global cancer statistics, 2012. CACancer J Clin 2015;65:87-108.

2. Zauber AG, Winawer SJ, O'Brien MJ, et al. Colonoscopic polypectomy and long-term prevention of colorectal-cancer deaths. N Engl J Med 2012;366:687-96.

3. Winawer SJ, Zauber AG, Ho MN, et al. Prevention of colorectal cancer by colonoscopic polypectomy. The National Polyp Study Workgroup. N Engl J Med 1993;329:1977-81.

4. Ferlitsch M, Moss A, Hassan C, et al. Colorectal polypectomy and endoscopic mucosal resection (EMR): European Society of Gastrointestinal Endoscopy (ESGE) Clinical Guideline. Endoscopy 2017;49:270-97.

5. Rutter MD, Chattree A, Barbour JA, et al. British Society of Gastroenterology/Association of Coloproctologists of Great Britain and Ireland guidelines for the management of large non-pedunculated colorectal polyps. Gut 2015;64:1847-73.

6. Moss A, Williams SJ, Hourigan LF, et al. Long-term adenoma recurrence following wide-field endoscopic mucosal resection (WF-EMR) for advanced colonic mucosal neoplasia is infrequent: results and risk factors in 1000 cases from the Australian Colonic EMR (ACE) study. Gut2015;64:57-65.

7. Buess G, Kipfmuller K, Hack D, et al. Technique of transanal endoscopic microsurgery. Surg Endosc 1988;2:71-5.

8. Moore JS, Cataldo PA, Osler T, etal. Transanal endoscopic microsurgery is more effective than traditional transanal excision for resection of rectal masses. Dis Colon Rectum 2008;51:1026-30; discussion 1030-1.

9. Moss A, Bourke MJ, Williams SJ, et al. Endoscopic mucosal resection outcomes and prediction of submucosal cancer from advanced colonic mucosal neoplasia. Gastroenterology 2011;140:1909-18.

10. Kudo S, Lambert R, Allen JI, et al. Nonpolypoid neoplastic lesions of the colorectal mucosa. Gastrointest Endosc 2008;68(4 Suppl):S3-47.

11. Ramirez JM, Aguilella V, Gracia JA, et al. Local full-thickness excision as first line treatment for sessile rectal adenomas: long-term results. Ann Surg 2009;249:225-8.

12. Guerrieri M, Baldarelli M, de Sanctis A, et al. Treatment of rectal adenomas by transanal endoscopic microsurgery: 15 years' experience. Surg Endosc 2010;24:445-9.

13. Barendse RM, Musters GD, de Graaf EJR, et al. Randomised controlled trial of transanal endoscopic microsurgery versus 
endoscopic mucosal resection for large rectal adenomas (TREND Study). Gut. Epub 2017 Jun 28.

14. van den Broek FJ, de Graaf EJ, Dijkgraaf MG, et al. Transanal endoscopic microsurgery versus endoscopic mucosal resection for large rectal adenomas (TREND-study). BMC Surg 2009;9:4.

15. Participants inthe Paris Workshop. The Parisendoscopic classification of superficial neoplastic lesions: esophagus, stomach, and colon: November 30 to December 1, 2002. Gastrointest Endosc 2003;58(6 Suppl):S3-43.

16. Kudo S, Tamura S, Nakajima T, et al. Diagnosis of colorectal tumorous lesions by magnifying endoscopy. Gastrointest Endosc 1996;44:8-14.

17. Marusch F, Ptok H, Sahm M, et al. Endorectal ultrasound in rectal carcinoma-do the literature results really correspond to the realities of routine clinical care? Endoscopy 2011;43:425-31.

18. Dutch Colorectal Cancer Guideline, Dutch Working Group Gastrointestinal Tumors, Oncoline Cancer Clinical Practice Guidelines, 2014.

19. Karita M, Tada M, Okita K, et al. Endoscopic therapy for early colon cancer: the strip biopsy resection technique. Gastrointest Endosc 1991;37: 128-32.

20. Hurlstone DP, Sanders DS, Cross SS, et al. A prospective analysis of extended endoscopic mucosal resection for large rectal villous adenomas: an alternative technique to transanal endoscopic microsurgery. Colorectal Dis 2005;7:339-44.

21. Sobin LH, Fleming ID. TNM classification of malignant tumors, fifth edition (1997). Union Internationale Contre le Cancer and the American Joint Committee on Cancer. Cancer 1997;80:1803-4.

22. Kaminski MF, Hassan C, Bisschops R, et al. Advanced imaging for detection and differentiation of colorectal neoplasia: European Society of Gastrointestinal Endoscopy (ESGE) Guideline. Endoscopy 2014;46: 435-49.

23. Bianco MA, Rotondano G, Marmo R, etal. Predictive value of magnification chromoendoscopy for diagnosing invasive neoplasia in nonpolypoid colorectal lesions and stratifying patients for endoscopic resection or surgery. Endoscopy 2006;38:470-6.

24. Hayashi N, Tanaka S, Hewett DG, et al. Endoscopic prediction of deep submucosal invasive carcinoma: validation of the narrow-band imaging international colorectal endoscopic (NICE) classification. Gastrointest Endosc 2013;78:625-32.

25. van der Vlugt M, van Doorn SC, Wang J, etal. Optical diagnosis of malignant colorectal polyps: is it feasible? Endosc Int Open 2016;4: E778-83.
Gondal G, Grotmol T, HofstadB, etal. Biopsy of colorectal polyps is not adequate for grading of neoplasia. Endoscopy 2005;37:1193-7.

27. Puli SR, Bechtold ML, Reddy JB, et al. Can endoscopic ultrasound predictearly rectal cancers that can be resected endoscopically? A metaanalysis and systematic review. Dig Dis Sci 2010;55:1221-9.

28. Kobayashi N, Saito Y, Sano Y, et al. Determining the treatment strategy for colorectal neoplastic lesions: endoscopic assessment or the nonlifting sign for diagnosing invasion depth? Endoscopy 2007;39:701-5.

29. Kim HG, Thosani N, Banerjee S, et al. Effect of prior biopsy sampling, tattoo placement, and snare sampling on endoscopic resection of large nonpedunculated colorectal lesions. Gastrointest Endosc 2015;81:204-13.

30. Bach SP, Hill J, Monson JR, et al. A predictive model for local recurrence after transanal endoscopic microsurgery for rectal cancer. $\mathrm{Br} \mathrm{J}$ Surg 2009;96:280-90.

31. Bosch SL, Teerenstra S, de Wilt JH, et al. Predicting lymph node metastasis in PT1 colorectal cancer: a systematic review of risk factors providing rationale for therapy decisions. Endoscopy 2013;45:827-34.

32. Glimelius B, Tiret E, Cervantes A, et al. Rectal cancer: ESMO Clinical Practice Guidelines for diagnosis, treatment and follow-up. Ann Oncol 2013;24(Suppl 6):vi81-8.

33. Ikematsu $H$, Yoda $Y$, Matsuda $T$, et al. Long-term outcomes after resection for submucosal invasive colorectal cancers. Gastroenterology 2013;144:551-9; quiz e14.

34. Nozawa H, Ishihara S, Fujishiro M, et al. Outcome of salvage surgery for colorectal cancer initially treated by upfront endoscopic therapy. Surgery 2016;159:713-20.

35. Hahnloser D, Wolff BG, Larson DW, et al. Immediate radical resection after local excision of rectal cancer: an oncologic compromise? Dis CoIon Rectum 2005;48:429-37.

36. Borstlap WA, Coeymans TJ, Tanis PJ, etal. Meta-analysis of oncological outcomes after local excision of pT1-2 rectal cancer requiring adjuvant (chemo)radiotherapy or completion surgery. Br J Surg 2016;103: 1105-16.

37. Hompes R, McDonald R, Buskens C, et al. Completion surgery following transanal endoscopic microsurgery: assessment of quality and shortand long-term outcome. Colorectal Dis 2013;15:e576-81.

38. Levic K, Bulut $\mathrm{O}$, Hesselfeldt $\mathrm{P}$, et al. The outcome of rectal cancer after early salvage TME following TEM compared with primary TME: a casematched study. Tech Coloproctol 2013;17:397-403.

26. 
SUPPLEMENTARY TABLE 1. Presurgical and postsurgical tumor staging of the patients who underwent completion surgery

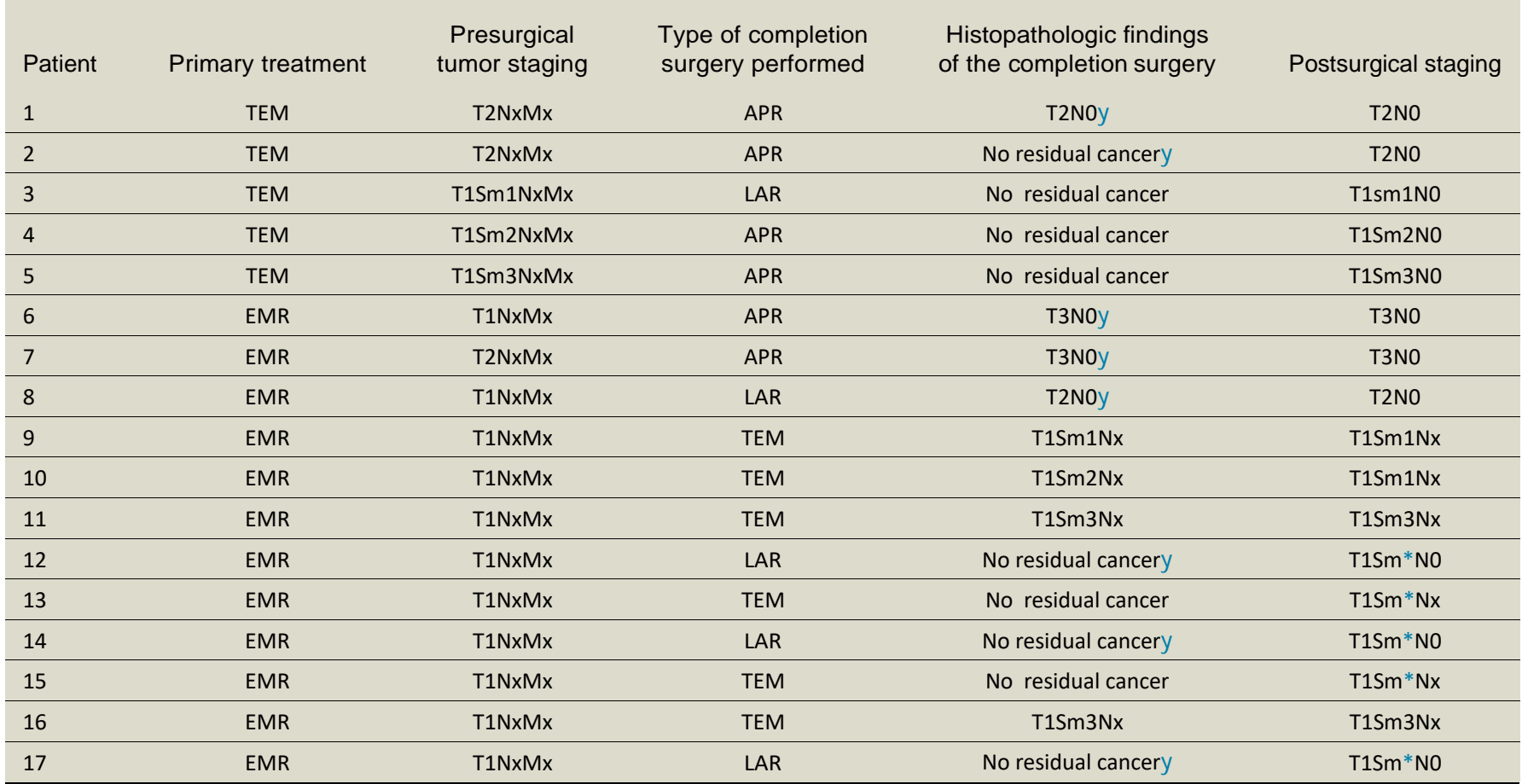

TEM, Transanal endoscopic microsurgery; APR, abdomino-perineal resection; LAR, low anterior resection.

*Sm depth was not assessable.

yReceived neoadjuvant radiotherapy. 